\title{
Kaempferol nanoparticles achieve strong and selective inhibition of ovarian cancer cell viability
}

This article was published in the following Dove Press journal:

International Journal of Nanomedicine

23 July 2012

Number of times this article has been viewed

\author{
Haitao Luo' \\ Bingbing Jiang ${ }^{2}$ \\ Bingyun $\mathrm{Li}^{2-4}$ \\ Zhaoliang $\mathrm{Li}^{\prime}$ \\ Bing-Hua Jiang ${ }^{5}$ \\ Yi Charlie Chen' \\ 'Department of Biology, Natural \\ Science Division, Alderson-Broaddus \\ College, Philippi, ${ }^{2}$ Department of \\ Orthopaedics, School of Medicine, \\ West Virginia University, ${ }^{3} \mathrm{WVNano}$ \\ Initiative, ${ }^{4}$ Mary Babb Randolph \\ Cancer Center, Morgantown,WV, \\ USA; ${ }^{5}$ Department of Pathology, \\ Anatomy and Cell Biology, Thomas \\ Jefferson University, Philadelphia, \\ PA, USA
}

Correspondence: Bingyun Li Biomaterials, Bioengineering, and Nanotechnology Laboratory, Mary Babb Randolph Cancer Center and Department of Orthopaedics, School of Medicine, West Virginia University, Morgantown, WV 26506-9196, USA

Tel +l 3042931075

Fax + I 3042937070

Email bli@hsc.wvu.edu

Yi Charlie Chen

Department of Biology, Natural Science Division Alderson-Broaddus College,

Philippi,WV 26416, USA

Tel +I 3044576277

Fax +I 3044576239

Email chenyc@ab.edu
Abstract: Ovarian cancer is one of the leading causes of cancer death for women throughout the Western world. Kaempferol, a natural flavonoid, has shown promise in the chemoprevention of ovarian cancer. A common concern about using dietary supplements for chemoprevention is their bioavailability. Nanoparticles have shown promise in increasing the bioavailability of some chemicals. Here we developed five different types of nanoparticles incorporating kaempferol and tested their efficacy in the inhibition of viability of cancerous and normal ovarian cells. We found that positively charged nanoparticle formulations did not lead to a significant reduction in cancer cell viability, whereas nonionic polymeric nanoparticles resulted in enhanced reduction of cancer cell viability. Among the nonionic polymeric nanoparticles, poly(ethylene oxide)-poly(propylene oxide)-poly(ethylene oxide) (PEO-PPO-PEO) nanoparticles incorporating kaempferol led to significant reduction in cell viability of both cancerous and normal cells. Poly(DL-lactic acid-co-glycolic acid) (PLGA) nanoparticles incorporating kaempferol resulted in enhanced reduction of cancer cell viability together with no significant reduction in cell viability of normal cells compared with kaempferol alone. Therefore, both PEO-PPO-PEO and PLGA nanoparticle formulations were effective in reducing cancer cell viability, while PLGA nanoparticles incorporating kaempferol had selective toxicity against cancer cells and normal cells. A PLGA nanoparticle formulation could be advantageous in the prevention and treatment of ovarian cancers. On the other hand, PEO-PPO-PEO nanoparticles incorporating kaempferol were more effective inhibitors of cancer cells, but they also significantly reduced the viability of normal cells. PEO-PPO-PEO nanoparticles incorporating kaempferol may be suitable as a cancer-targeting strategy, which could limit the effects of the nanoparticles on normal cells while retaining their potency against cancer cells. We have identified two nanoparticle formulations incorporating kaempferol that may lead to breakthroughs in cancer treatment. Both PEO-PPOPEO and PLGA nanoparticle formulations had superior effects compared with kaempferol alone in reducing cancer cell viability.

Keywords: nanochemoprevention, kaempferol, ovarian cancer, nanoparticles, viability, natural compound

\section{Introduction}

Natural compounds with antioxidant properties that function to protect the human body against development of cancer ${ }^{1,2}$ are present in a variety of fruit and vegetables. ${ }^{3}$ Natural dietary compounds have been reported to reduce the risk of development of diabetes, ${ }^{4}$ cardiovascular disease, ${ }^{5}$ prostate cancer, ${ }^{6}$ colorectal cancer, ${ }^{7}$ and ovarian cancer. ${ }^{8}$ Kaempferol (3,5,7-trihydroxy-2-(4-hydroxyphenyl)-4H-1-benzopyran-4-one) is a relatively common nontoxic, natural dietary compound which has been reported to reduce the risk of ovarian cancer. ${ }^{9}$ Kaempferol was found to inhibit estrogen 
receptor alpha expression in breast cancer cells ${ }^{10}$ and to induce apoptosis in glioblastoma cells ${ }^{11}$ and lung cancer cells $^{12}$ by activation of MEK-MAPK. Studies have shown that kaempferol also has anti-inflammatory effects via inhibition of interleukin- $4^{13}$ and cyclo-oxygenase 2 expression by suppressing Src kinase ${ }^{14}$ and downregulating the NFKB pathway. ${ }^{15}$ Kaempferol is also effective in inhibiting angiogenesis and inducing apoptosis in ovarian cancer cells. ${ }^{16-19}$ In human studies, a significant $40 \%$ decrease in incidence of ovarian cancer was found for individuals with the highest quintile of kaempferol intake as compared with those in the lowest quintile. ${ }^{20}$ Despite promising preclinical results, the utility of such compounds for chemoprevention in humans has met with only limited success, largely due to inefficient systemic delivery and limited bioavailability of promising agents. Therefore, to achieve the maximum response to a chemopreventive agent, novel strategies are required to enhance the bioavailability of potentially useful agents and to reduce toxicity.

Nanotechnology is an emerging interdisciplinary field that encompasses biology, engineering, chemistry, and medicine. ${ }^{21}$ Using nanotechnology for the development of efficient anticancer drug delivery systems is a recent advance in medical science. ${ }^{22-24}$ The ability of nanoparticles to incorporate entities renders them ideal carriers for various anticancer drugs. ${ }^{25,26}$ Because most anticancer drugs have poor solubility in water and low bioavailability, the use of nanocarriers enables cancer medications with low solubility in water to be prepared as solid or liquid formulations. Nanoparticles comprised of biodegradable polymers have been studied for delivery of drugs. ${ }^{27,28}$ Significant advantages of using biodegradable polymers are their safety and the ability to control the time and rate of polymer degradation as well as timely release of the drug. Nanoparticles comprised of biodegradable polymers such as poly(lactic acid), poly(DLlactic acid-co-glycolic acid) (PLGA), poly(caprolactone), palmitic acid, and chitosan have been utilized for the delivery of anticancer drugs. ${ }^{27,28}$ In recent years, nanotechnology has been implemented and assessed in different areas of cancer therapeutics and management. ${ }^{29}$ Siddiqui et al reported that nanoencapsulated epigallocatechin-3-gallate retains its biological effectiveness, with over a 10 -fold dose reduction advantage compared with nonencapsulated epigallocatechin-3-gallate when inhibiting cell growth, and proapoptotic and angiogenic effects. ${ }^{30}$

Ovarian cancer is one of the leading causes of cancer death in women throughout the Western world. ${ }^{31}$ There has been limited progress in the prevention, early diagnosis, and treatment of ovarian cancer to date, ${ }^{32,33}$ leaving this malignancy with an unchanged death rate over decades. ${ }^{31}$ Chemoprevention of ovarian cancer using natural products has received more attention recently, and our earlier studies have indicated that kaempferol, a dietary flavonoid, is effective in inhibiting angiogenesis and inducing apoptosis in ovarian cancer cells. ${ }^{16-19}$ However, effective concentrations are often above $20-40 \mu \mathrm{M}$, which are not always physiologically attainable. In this study, five nanoparticle formulations of kaempferol were developed and their efficacy in inhibiting the viability of malignant and normal ovarian cells was determined.

\section{Materials and methods Chemicals}

Kaempferol (soluble, $50 \mathrm{mg} / \mathrm{mL}$ in dimethyl sulfoxide), polyethylenimine (PEI, molecular weight $800 \mathrm{Da}$ ), PLGA (lactide to glycolide ratio 50:50, molecular weight 30-60 kDa), glycol chitosan, poly(amidoamine) (PAMAM) dendrimer (molecular weight 516), and polyvinyl alcohol (molecular weight 31-50 kDa), tetrahydrofuran, ethanol, acetone, dimethyl sulfoxide, and Dulbecco's phosphate-buffered saline solution were purchased from Sigma-Aldrich (St Louis, MO). Poly(ethylene oxide)-poly(propylene oxide)-poly(ethylene oxide) (PEO-PPO-PEO, Pluronic P123 surfactant) was obtained from BASF Corporation (Mount Olive, NJ). The chemical structures of kaempferol, PLGA, PEO-PPO-PEO, glycol chitosan or chitosan, PLGA-PEI, and PAMAM dendrimer are shown in Figure 1. The PLGA-PEI polymer was synthesized using an aminolysis approach. In brief, PLGA was dissolved in tetrahydrofuran and PEI was dissolved in ethanol. The two solutions were then mixed at a PLGA to PEI mass ratio of $10: 1$ and stirred at $50^{\circ} \mathrm{C}$ for 30 minutes to form PLGA-PEI. The polymer solution was then dialyzed using a $2 \mathrm{kDa}$ dialysis membrane for 2 days and lyophilized.

\section{Synthesis and characterization of nanoparticles incorporating kaempferol} The PEO-PPO-PEO, PLGA, PLGA-PEI, chitosan, and PAMAM nanoparticles were studied, and found to be biodegradable and to have good biocompatibility with normal cells and tissues. These five nanoparticles incorporated with and without kaempferol were synthesized using a nanoprecipitation method ${ }^{34}$ In brief, kaempferol was dissolved in dimethyl sulfoxide at a concentration of $0.2 \mathrm{M}$. PLGA, PAMAM, PEO-PPO-PEO, and PLGA-PEI were dissolved in acetone at a concentration of $20 \mathrm{~g} / \mathrm{L}$. Chitosan was dissolved in deionized water at a concentration of $200 \mathrm{~g} / \mathrm{L}$ and further mixed 
<smiles>O=c1c(O)c(-c2ccc(O)cc2)oc2cc(O)cc(O)c12</smiles>

Kaempferol<smiles>CC(C)(C)OC(=O)CC(C)(C)C(=O)OC(C)(C)C</smiles>

PLGA<smiles>CC(COCCC(C)(C)C)C(C)(C)OCCC(C)(C)C</smiles>

PEO-PPO-PEO<smiles>CC(C)(P)CCNC(C)(C)CC(=O)OC(C)(C)CC(=O)OC(C)(C)C(=O)C1CC2(C)CC1(C)C2</smiles>

or<smiles>CC(C(=O)OCC(C)(C)CC(=O)CC(C)(C)C)C(C)C(=O)OCC(C)(C)NCCC(C)(C)C</smiles>

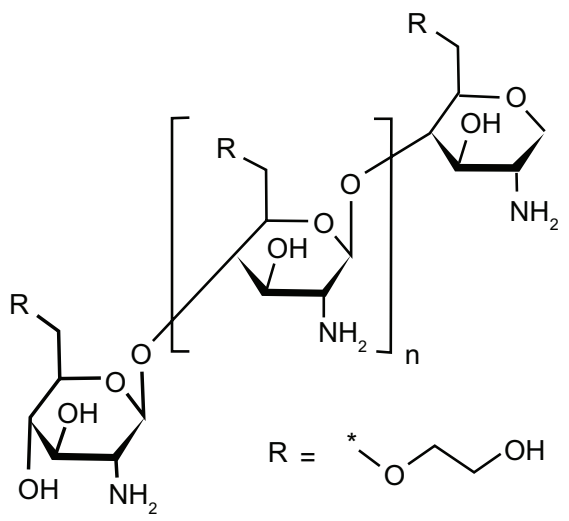

Glycol chitosan<smiles>NCCCN(CCCN(CCC(=O)NCCN)CCC(=O)NCCN)CCC(=O)NCCN</smiles>

PAMAM dendrimer

\section{PLGA-PEI}

Figure I Chemical structures of kaempferol, PLGA, PEO-PPO-PEO, glycol chitosan, PLGA-PEI, and PAMAM dendrimer.

Abbreviations: PEO-PPO-PEO, poly(ethylene oxide)-poly(propylene oxide)-poly(ethylene oxide); PLGA, poly(DL-lactic acid-co-glycolic acid); PEI, polyethyleneimine; PAMAM, poly(amidoamine).

with acetone to $20 \mathrm{~g} / \mathrm{L}$ before synthesis of the nanoparticles. To synthesize the nanoparticles incorporating kaempferol, $250 \mu \mathrm{L}$ of kaempferol solution was mixed with $1 \mathrm{~mL}$ of polymer solution. Five mL of Dulbecco's phosphate-buffered saline solution was added dropwise and gently stirred with a magnetic bar for 30 minutes. The solution was kept under ventilation for 6 hours and then gradually vacuumed until no vapor was observed. The resulting solution was concentrated at $2.5 \mathrm{mM}$ under a speed vacuum concentrator (Thermo Fisher Scientific, Waltham, MA) or lyophilized as a powder; for 
lyophilized samples, Dulbecco's phosphate-buffered saline solution was replaced with deionized water. To prepare the PLGA nanoparticles, polyvinyl alcohol was used as a surfactant and added in Dulbecco's phosphate-buffered saline solution at a concentration of $0.5 \mathrm{wt} \%$. Nanoparticles incorporating kaempferol were diluted and their size and surface potential were characterized using a 2000 Zetasizer (Malvern Instruments, Worcestershire, UK).

\section{Cell culture}

IOSE397 cells are normal ovarian surface epithelial cells immortalized with SV40 T/t, and were gifted for this research by Dr Nelly Auersperg, University of British Columbia, Canada. A2780/CP70 and OVCAR-3 ovarian cancer cell lines were from Dr Bing-Hua Jiang at Thomas Jefferson University, Philadelphia, PA. All cells were maintained in RPMI 1640 medium (Sigma-Aldrich) supplemented with $10 \%$ fetal bovine serum (Life Technologies, Carlsbad, CA) at $37^{\circ} \mathrm{C}$ with $5 \% \mathrm{CO}_{2}$.

\section{Cell viability assay}

Kaempferol alone, nanoparticles without kaempferol, kaempferol mixed with but not incorporated into nanoparticles, and nanoparticles incorporating kaempferol were tested for their effects on the viability of malignant and/or normal ovarian cells. To test the effects of kaempferol alone and nanoparticles incorporating kaempferol, the cells were seeded in microplates at 8000 cells per well, incubated at $37^{\circ} \mathrm{C}$ overnight, and treated with kaempferol or nanoparticles for 24 hours. Cell viability was analyzed using a CellTiter 96 Aqueous one solution cell proliferation assay kit from Promega Corporation (Madison, WI). Optical density (OD) values were recorded at $490 \mathrm{~nm}$.

\section{Statistical analysis}

The results were expressed as the mean \pm standard error of the mean. During the screening process, optical density values were compared by $t$-test. For indepth analysis of selected nanoparticles, independent experiments were normalized and combined for statistical analysis. Statistical significance was set at $P<0.05$.

\section{Results and discussion}

The synthesized PEO-PPO-PEO, PLGA, PLGA-PEI, chitosan, and PAMAM nanoparticles were approximately $200 \mathrm{~nm}$ in size (Table 1). The PEO-PPO-PEO and PLGA nanoparticles had almost no surface charge, while chitosan, PLGAPEI, and PAMAM nanoparticles had a positive surface charge, with PAMAM having the highest charge (Table 1).
Table I Particle size and zeta potential of nanoparticles incorporating kaempferol (data are an average of three samples)

\begin{tabular}{llc}
\hline Nanoparticle & Particle size $(\mathbf{n m})$ & Surface potential $(\mathbf{m V})$ \\
\hline PLGA & $210 \pm 40$ & $+0.1 \pm 3.4$ \\
PEO-PPO-PEO & $160 \pm 30$ & $+1.4 \pm 4.2$ \\
Chitosan & $230 \pm 70$ & $+11.7 \pm 5.9$ \\
PLGA-PEI & $220 \pm 50$ & $+34.2 \pm 7.9$ \\
PAMAM & $250 \pm 70$ & $+37.2 \pm 8.3$ \\
\hline
\end{tabular}

Abbreviations: PEO-PPO-PEO, poly(ethylene oxide)-poly(propylene oxide)-poly (ethylene oxide); PLGA, poly(DL-lactic acid-co-glycolic acid); PEI, polyethyleneimine; PAMAM, poly(amidoamine).

We screened the five different types of kaempferol nanoparticles for their ability to inhibit viability of A2780/ CP70 cancer cells. As shown in Figure 2A-F, kaempferol in $25 \mu \mathrm{M}$ phosphate-buffered saline solution did not achieve any significant reduction in cell viability compared with unexposed controls. Neither nanoparticles plus kaempferol nor nanoparticles alone resulted in any significant change in A2780/CP70 cell viability compared with kaempferol in phosphate-buffered saline solution or the control. In contrast, PEO-PPO-PEO nanoparticles incorporating kaempferol achieved significant inhibition of A2780/CP70 cells and resulted in significant reduction in cell viability compared with kaempferol in phosphate-buffered saline solution (Figure 2A). PLGA nanoparticles incorporating kaempferol also showed marginally significant inhibitory effects compared with kaempferol in phosphate-buffered saline solution $(P=0.07$, Figure 2B). The other three types of nanoparticle (ie, PLGA-PEI, chitosan, and PAMAM) did not achieve a significant reduction in A2780/CP70 cell viability compared with kaempferol in phosphate-buffered saline solution or the control, and no significant differences in ability to reduce cell viability were observed between these three nanoparticle types (Figure 2F).

These data suggest that nanoparticle chemistry plays an important role in the treatment of cancer if nanoparticles are used. Appropriate nanoparticle formulation or chemistry (ie, PEO-PPO-PEO) can lead to significant reduction of cancer cell viability (see Figure 1A). Positively charged nanoparticles did not result in reduction of A2780/CP70 cell viability, while nonionic polymeric (eg, PEO-PPO-PEO) nanoparticles led to significant reduction in A2780/CP70 cell viability.

We also examined these chemicals in another ovarian cancer cell line (ie, OVCAR-3). Consistent with the screening results for A2780/CP70 cells, PEO-PPO-PEO and PLGA nanoparticles incorporating kaempferol resulted in significantly lower OVCAR-3 cell viability compared with kaempferol in phosphate-buffered saline solution and the control (Figure 3). PLGA-PEI, chitosan, and PAMAM 
A

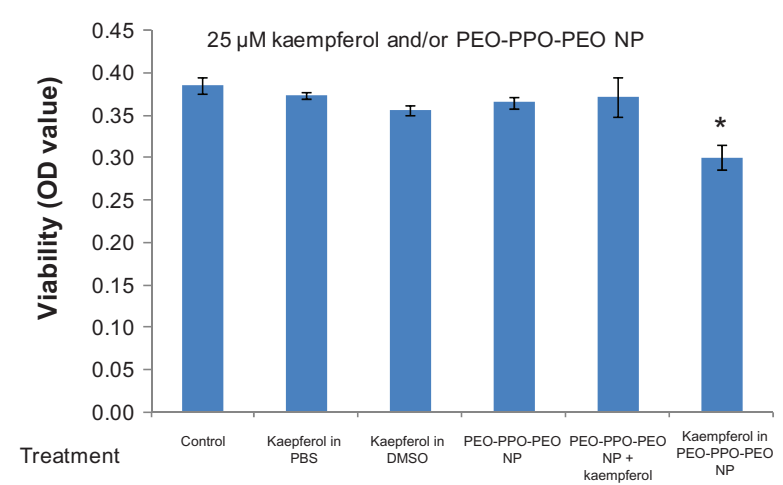

C

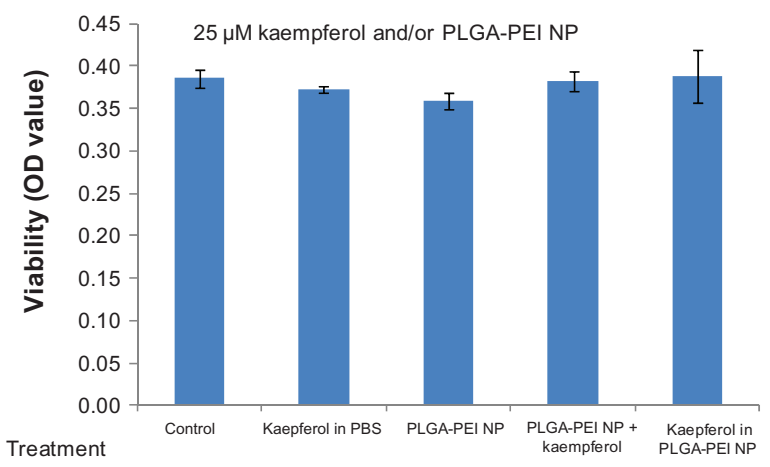

E

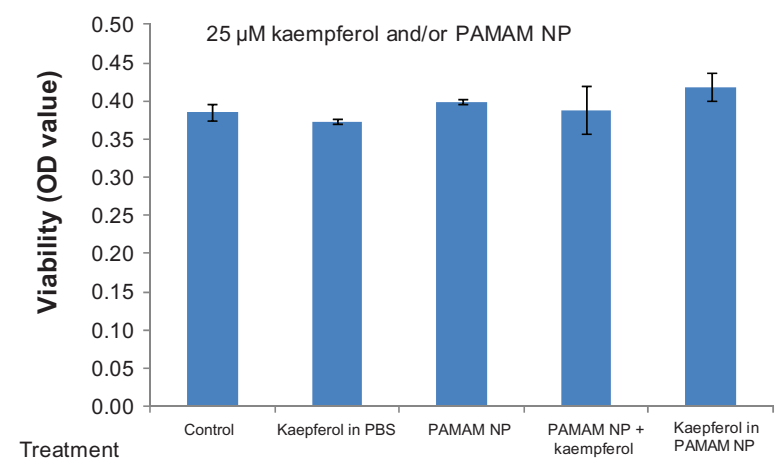

B

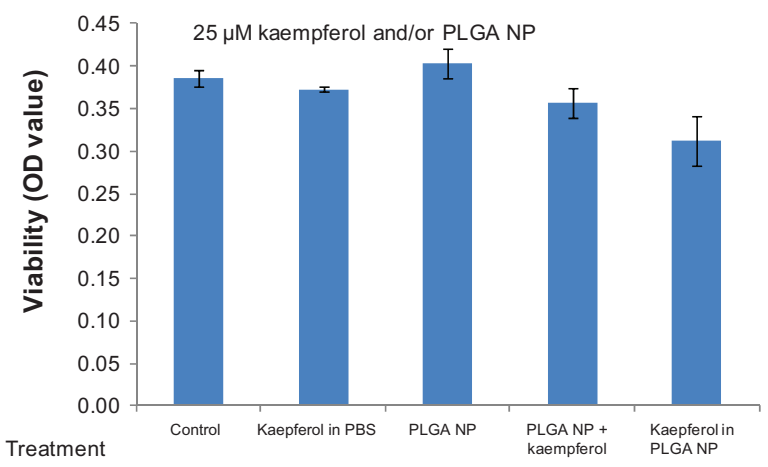

D

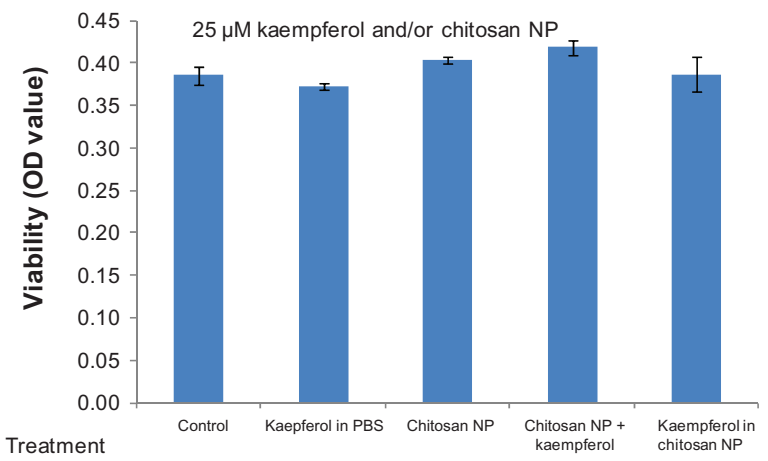

Figure 2 Effects of nanoparticles incorporating kaempferol on A2780/CP70 ovarian cancer cells.

Notes: Ovarian cancer cells were seeded in a microplate, incubated overnight, and treated with $25 \mu \mathrm{M}$ kaempferol for 24 hours. Cell viability was analyzed using an MTS-based method. $* P<0.05$ as compared with kaempferol in phosphate-buffered saline solution and control.

Abbreviations: MTS, 3-(4,5-dimethylthiazol-2-yl)-5-(3-carboxymethoxyphenyl)-2-(4-sulfophenyl)-2H-tetrazolium; NP, nanoparticle; OD, optical density; PEO-PPO-PEO, poly(ethylene oxide)-poly(propylene oxide)-poly(ethylene oxide); PAMAM, poly(amidoamine); PBS, phosphate-buffered saline solution; PLGA, poly(DL-lactic acid-co-glycolic acid).

nanoparticles resulted in higher cell viability compared with kaempferol in phosphate-buffered saline solution (Figure 3). Comparing Figures $2 \mathrm{~F}$ and 3, PEO-PPO-PEO and PLGA nanoparticles incorporating kaempferol led to lower viability of both A2780/CP70 and OVCAR-3 cancer cells than did kaempferol in phosphate-buffered saline solution, but the degree of reduction was significantly different. Moreover, PEO-PPO-PEO and PLGA nanoparticles incorporating kaempferol showed greater activity against OVCAR-3 cells than A270/CP70 cells. This is consistent with the effect of kaempferol alone because kaempferol $25 \mu \mathrm{M}$ in phosphate-buffered saline solution significantly 


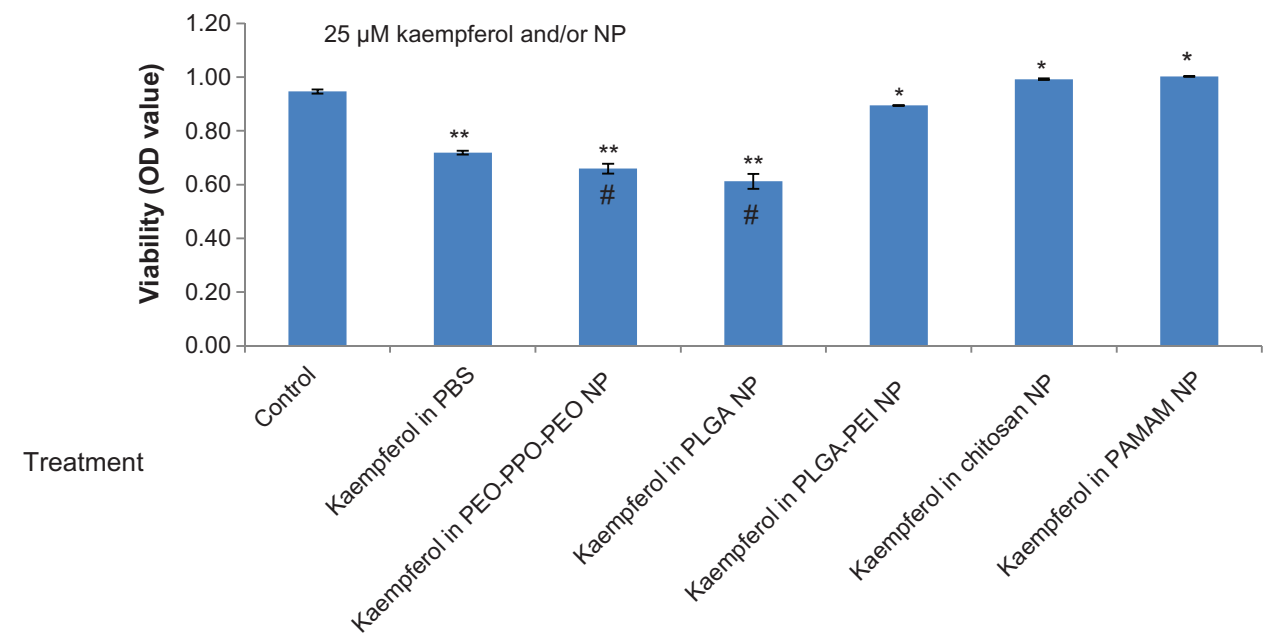

Figure 3 Effects of nanoparticles incorporating kaempferol on OVCAR-3 ovarian cancer cells.

Notes: OVCAR-3 cells were seeded in a microplate, incubated overnight, and treated with $25 \mu \mathrm{M}$ kaempferol for 24 hours. Cell viability was analyzed using an MTS-based method. ${ }^{* *} P<0.01, * P<0.05$ versus control. ${ }^{*} P<0.01$ versus kaempferol in phosphate-buffered saline solution.

Abbreviations: NP, nanoparticle; OD, optical density; PEO-PPO-PEO, poly(ethylene oxide)-poly(propylene oxide)-poly(ethylene oxide); PAMAM, poly(amidoamine); PBS, phosphate-buffered saline solution; PLGA, poly(DL-lactic acid-co-glycolic acid).

reduced the viability of OVCAR-3 cells (Figure 3 ) but not A2780/CP70 cells (Figure 2F). These findings suggest that the treatment outcome depends on the type of cancer cell, and PEO-PPO-PEO and PLGA nanoparticles incorporating kaempferol could have potential application in different forms of ovarian cancer (even when kaempferol alone does not have a significant impact).

The effects of PEO-PPO-PEO and PLGA nanoparticles incorporating kaempferol were further compared with kaempferol in phosphate-buffered saline solution for their inhibitory effects on cancerous and normal ovarian cells at two different concentrations $(10 \mu \mathrm{M}$ and $25 \mu \mathrm{M})$. As shown in Figure 4, at $10 \mu \mathrm{M}$, PLGA nanoparticles incorporating kaempferol significantly reduced the viability of OVCAR-3 cells but had no significant influence on the viability of IOSE397 cells. This result was also found at the $25 \mu \mathrm{M}$ concentration. However, PEO-PPO-PEO nanoparticles incorporating kaempferol significantly reduced the viability of both OVCAR-3 and IOSE397 cells compared with kaempferol in phosphate-buffered saline solution at concentrations of $10 \mu \mathrm{M}$ and $25 \mu \mathrm{M}$. Overall, the higher the concentration (from $10 \mu \mathrm{M}$ to $25 \mu \mathrm{M}$ ), the greater the reduction in OVCAR-3 cell viability. Moreover, it seemed that, at the same concentration, PEO-PPO-PEO nanoparticles incorporating kaempferol were more effective in reducing OVCAR-3 cell viability compared with PLGA nanoparticles incorporating kaempferol, with a significant reduction seen at $10 \mu \mathrm{M}$ (Figure 4A). PEO-PPO-PEO
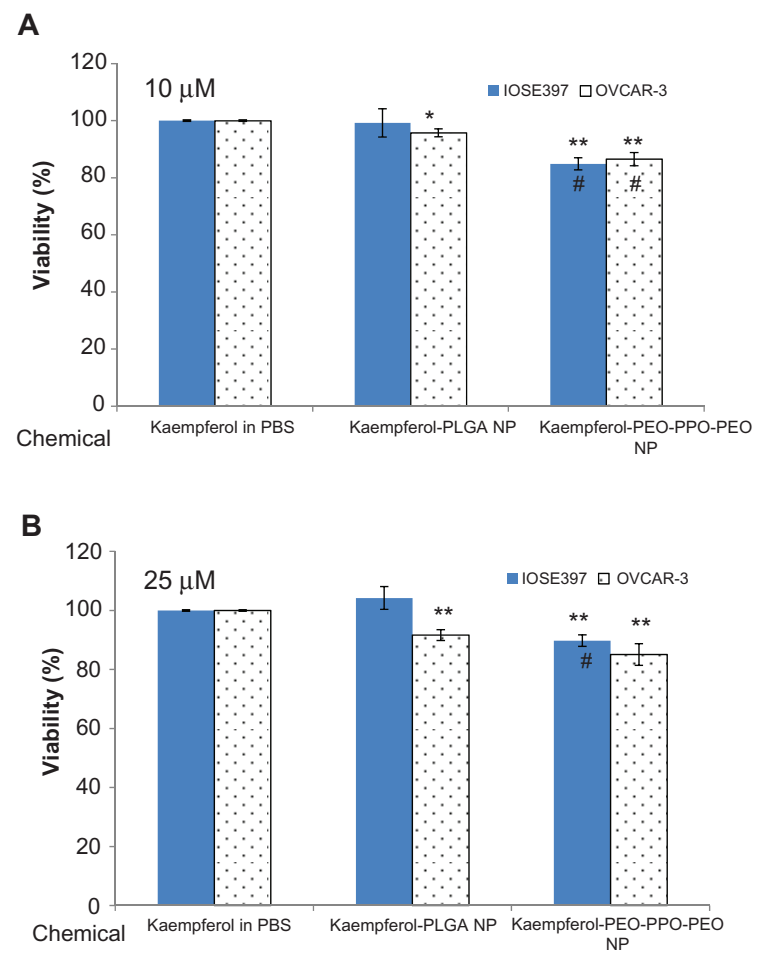

Figure 4 Effects of PEO-PPO-PEO and PLGA nanoparticles incorporating kaempferol on OVCAR-3 ovarian cancer cells and immortalized IOSE397 epithelial ovarian cells at (A) $10 \mu \mathrm{M}$ and (B) $25 \mu \mathrm{M}$. Ovarian cells were seeded in microplates, incubated overnight, and treated with kaempferol or its nanoparticles for 24 hours. Notes: Viability of cells was measured using an MTS-based method. Data represent the mean \pm standard error of the mean from a minimum of three independent experiments. ${ }^{*} P<0.05$, ${ }^{* *} P<0.01$ versus kaempferol in phosphate-buffered saline solution. ${ }^{*} P<0.01$ versus PLGA nanoparticles incorporating kaempferol in treating the same cell type. Abbreviations: MTS, 3-(4,5-dimethylthiazol-2-yl)-5-(3-carboxymethoxyphenyl)-2-(4sulfophenyl)-2H-tetrazolium; PBS, phosphate-buffered saline solution; NP, nanoparticle; PEO-PPO-PEO, poly(ethylene oxide)-poly(propylene oxide)-poly(ethylene oxide); PLGA, poly(DL-lactic acid-co-glycolic acid). 
Table 2 Summary of the effects of PEO-PPO-PEO and PLGA nanoparticles incorporating kaempferol on cancerous and normal ovarian cells studied

\begin{tabular}{lll}
\hline Cell & $\begin{array}{l}\text { Kaempferol-PLGA } \\
\text { NP }\end{array}$ & $\begin{array}{l}\text { Kaempferol- } \\
\text { PEO-PPO-PEO NP }\end{array}$ \\
\hline Cancer cell & & $\mathbb{\pi}$ \\
A2780/CP70 & $\S$ & $\mathbb{T}^{*}$ \\
OVCAR-3 & $\mathbb{T}$ & \\
$\begin{array}{l}\text { Normal cell } \\
\text { IOSE397 }\end{array}$ & $* *$ & $\mathbb{\pi}^{\wedge}$ \\
\hline
\end{tabular}

Notes: "Significant reduction in viability compared with kaempferol in PBS; snotable reduction $(P=0.07)$ in viability compared with kaempferol in PBS; **no significant difference in viability compared with kaempferol in PBS; *significant reduction in viability at a low concentration (ie, $10 \mu \mathrm{M}$ ) but not at a high concentration (ie, $25 \mu \mathrm{M}$ ) compared with kaempferol-PLGA nanoparticles; ^significant reduction in viability versus kaempferol-PLGA nanoparticles.

Abbreviations: PEO-PPO-PEO, poly(ethylene oxide)-poly(propylene oxide)poly(ethylene oxide); PLGA, poly(DL-lactic acid-co-glycolic acid); NP, nanoparticle; PBS, phosphate-buffered saline solution.

nanoparticles incorporating kaempferol also resulted in significant reduction of IOSE397 cell viability compared with PLGA nanoparticles incorporating kaempferol (Figure 4). These results suggest that incorporation of kaempferol into PEO-PPO-PEO and PLGA nanoparticles enhanced the effectiveness of kaempferol in reducing the viability of cancer cells, and PEO-PPO-PEO nanoparticles incorporating kaempferol were more effective than PLGA nanoparticles incorporating kaempferol. PLGA nanoparticles incorporating kaempferol could discriminate between cancerous and normal cells, whereby the viability of cancer cells but not the normal cells was significantly affected by PLGA nanoparticles incorporating kaempferol compared with kaempferol alone.

It is worth mentioning that developing effective strategies for targeting anticancer drugs or nanoparticles has also attracted attention. ${ }^{35-39}$ Sunoqrot et al recently reported a hybrid nanoparticle platform that may allow targeting kinetics to be effectively controlled through hybridization of targeted dendrimers using polymeric nanoparticles. ${ }^{39}$ In their study, folate-targeted PAMAM dendrimers were incorporated into poly(ethylene glycol)- $b$-poly(D,Llactide) nanoparticles, and their combined passive and active targeting enabled precise control over the targeting kinetics of dendrimers to folate-overexpressing cells. ${ }^{39}$ Similarly, folate-targeted kaempferol complexes could be incorporated into our PEO-PPO-PEO or PLGA nanoparticles to achieve high targeting efficacy against folateoverexpressing cancerous cells while limiting potential effects on normal cells.
Conclusion

Five nanoparticle formulations incorporating kaempferol were investigated for their potential in the treatment of ovarian cancer, and their efficacy was tested in vitro. Table 2 summarizes the effects of PEO-PPO-PEO and PLGA nanoparticles incorporating kaempferol on cancerous and normal ovarian cells. In A2780/CP70 ovarian cancer cells, we found that nanoparticles incorporating kaempferol with positive charges (ie, PLGA-PEI, glycol chitosan, and PAMAM dendrimer) did not significantly reduce cell viability. PEO-PPO-PEO nanoparticles incorporating kaempferol significantly reduced cell viability compared with kaempferol alone, and PLGA nanoparticles incorporating kaempferol also showed notably enhanced reduction of the viability of A2780/CP70 cells. PEO-PPO-PEO and PLGA nanoparticles incorporating kaempferol also significantly reduced the viability of OVCAR-3 cancer cells, compared with kaempferol alone. These two kaempferol nanoparticles were further compared with kaempferol alone in immortalized IOSE397 ovarian cells and OVCAR-3 ovarian cancer cells. We found that PEOPPO-PEO nanoparticles incorporating kaempferol not only significantly reduced the viability of OVCAR-3 cancer cells but also that of normal IOSE397 cells compared with kaempferol alone. Interestingly, PLGA nanoparticles incorporating kaempferol significantly reduced the viability of OVCAR-3 cancer cells but not normal IOSE397 cells compared with kaempferol alone. Therefore, the PLGA nanoparticle formulation could be a promising candidate for cancer treatment due to its improved ability to reduce cancer cell viability along with no significant reduction in the viability of normal ovarian cells. PEO-PPO-PEO nanoparticles incorporating kaempferol were more effective in inhibiting the viability of cancer cells compared with PLGA nanoparticles incorporating kaempferol. If appropriately targeted, PEO-PPO-PEO nanoparticles incorporating kaempferol could be more effective in treating cancer. The mechanisms related to the effects of PEO-PPO-PEO and PLGA nanoparticles incorporating kaempferol on cancerous and normal ovarian cells are still unclear, so further investigation of these nanoparticles for better nanochemoprevention of cancer is warranted.

\section{Acknowledgments}

This research was supported by a West Virginia Experimental Program to Stimulate Competitive Research grant and an NIH grant (P20 RR016477) from the National Center for Research Resources awarded to the West Virginia IDeA Network of Biomedical Research Excellence. BL also acknowledges 
financial support from the National Science Foundation (1003907), the West Virginia Higher Education Policy Commission/Division of Science Research, and WVNano. The authors thank Suzanne Smith for proofreading.

\section{Disclosure}

The authors report no conflicts of interest in this work.

\section{References}

1. Gonzalez CA, Riboli E. Diet and cancer prevention: where we are, where we are going. Nutr Cancer. 2006;56:225-231.

2. Holick CN, Giovannucci EL, Rosner B, Stampfer MJ, Michaud DS. Prospective study of intake of fruit, vegetables, and carotenoids and the risk of adult glioma. Am J Clin Nutr. 2007;85:877-886.

3. Bosetti C, Rossi M, McLaughlin JK, et al. Flavonoids and the risk of renal cell carcinoma. Cancer Epidemiol Biomarkers Prev. 2007;16:98-101.

4. Hanhineva K, Törrönen R, Bondia-Pons I, et al. Impact of dietary polyphenols on carbohydrate metabolism. Int J Mol Sci. 2010;11: 1365-1402.

5. Rudkowska I, Jones PJ. Functional foods for the prevention and treatment of cardiovascular diseases: cholesterol and beyond. Expert Rev Cardiovasc Ther. 2007;5:477-490.

6. Bosetti C, Bravi F, Talamini R, et al. Flavonoids and prostate cancer risk: a study in Italy. Nutr Cancer. 2006;56:123-127.

7. Theodoratou E, Kyle J, Cetnarskyj R, et al. Dietary flavonoids and the risk of colorectal cancer. Cancer Epidemiol Biomarkers Prev. 2007; 16:684-693.

8. Rossi M, Negri E, Lagiou P, et al. Flavonoids and ovarian cancer risk: a case-control study in Italy. Int J Cancer. 2008;123:895-898.

9. Duthie G, Crozier A. Plant-derived phenolic antioxidants. Curr Opin Clin Nutr Metab Care. 2000;3:447-451.

10. Hung $H$. Inhibition of estrogen receptor alpha expression and function in MCF-7 cells by kaempferol. J Cell Physiol. 2004;198:197-208.

11. Sharma V, Joseph C, Ghosh S, Agarwal A, Mishra MK, Sen E. Kaempferol induces apoptosis in glioblastoma cells through oxidative stress. Mol Cancer Ther. 2007;6:2544-2553.

12. Leung HW, Lin CJ, Hour MJ, Yang WH, Wang MY, Lee HZ. Kaempferol induces apoptosis in human lung non-small carcinoma cells accompanied by an induction of antioxidant enzymes. Food Chem Toxicol. 2007;45:2005-2013.

13. Cortes JR, Perez-GM, Rivas MD, Zamorano J. Kaempferol inhibits IL-4-induced STAT6 activation by specifically targeting JAK3. J Immunol. 2007;179:3881-3887.

14. Lee KM, Lee KW, Jung SK, et al. Kaempferol inhibits UVB-induced COX-2 expression by suppressing Src kinase activity. Biochem Pharmacol. 2010;80:2042-2049.

15. García-Mediavilla V, Crespo I, Collado PS, et al. The anti-inflammatory flavones quercetin and kaempferol cause inhibition of inducible nitric oxide synthase, cyclooxygenase-2 and reactive C-protein, and downregulation of the nuclear factor kappaB pathway in Chang Liver cells. Eur J Pharmacol. 2007;557:221-229.

16. Luo H, Rankin GO, Juliano N, Jiang BH, Chen YC. Kaempferol inhibits VEGF expression and in vitro angiogenesis through a novel ERK-NFKB-cMyc-p21 pathway. Food Chem. 2012;130:321-328.

17. Luo H, Rankin GO, Li Z, DePriest L, Chen YC. Kaempferol induces apoptosis in ovarian cancer cells through activating p53 in the intrinsic pathway. Food Chem. 2011;128:513-519.

18. Luo H, Rankin GO, Liu L, Daddysman MK, Jiang BH, Chen YC. Kaempferol inhibits angiogenesis and VEGF expression through both HIF dependent and independent pathways in human ovarian cancer cells. Nutr Cancer. 2009;61:554-563.
19. Luo H, Jiang BH, King SM, Chen YC. Inhibition of cell growth and VEGF expression in ovarian cancer cells by flavonoids. Nutr Cancer. 2008;60:800-809.

20. Gates MA, Tworoger SS, Hecht JL, De Vivo I, Rosner B, Hankinson SE. A prospective study of dietary flavonoid intake and incidence of epithelial ovarian cancer. Int J Cancer. 2007;121:2225-2232.

21. Ferrari M. Cancer nanotechnology: opportunities and challenges. Nat Rev Cancer. 2005;5:161-171.

22. Siddiqui IA, Adhami VM, Ahmad N, Mukhtar H. Nanochemoprevention: sustained release of bioactive food components for cancer prevention. Nutr Cancer. 2010;62:883-890.

23. Siddiqui IA, Adhami VM, Christopher J, Chamcheu, Mukhtar H. Impact of nanotechnology in cancer: emphasis on nanochemoprevention. Int J Nanomedicine. 2012;7:591-605.

24. Ma X, Wang H, Jin S, Wu Y, Liang XJ. Construction of paclitaxel-loaded poly (2-hydroxyethyl methacrylate)-g-poly (lactide)-1,2-dipalmitoylsn-glycero-3-phosphoethanolamine copolymer nanoparticle delivery system and evaluation of its anticancer activity. Int J Nanomedicine. 2012; 7:1313-1328.

25. Ranganathan R, Madanmohan S, Kesavan A, et al. Nanomedicine: towards development of patient-friendly drug-delivery systems for oncological applications. Int J Nanomedicine. 2012;7:1043-1060.

26. Sabnis N, Nair M, Israel M, McConathy WJ, Lacko AG. Enhanced solubility and functionality of valrubicin (AD-32) against cancer cells upon encapsulation into biocompatible nanoparticles. Int $J$ Nanomedicine. 2012;7:975-983.

27. Gref R, Minamitake Y, Peracchia MT, Trubetskoy V, Torchilin V, Langer R. Biodegradable long-circulating polymeric nanospheres. Science. 1994;263:1600-1603

28. Peer D, Karp JM, Hong S, Farokhzad OC, Margalit R, Langer R. Nanocarriers as an emerging platform for cancer therapy. Nat Nanotechnol. 2007;2:751-760.

29. Nishiyama N. Nanomedicine: nanocarriers shape up for long life. Nat Nanotechnol. 2007;2:203-204.

30. Siddiqui IA, Adhami VM, Bharali DJ, et al. Introducing nanochemoprevention as a novel approach for cancer control: proof of principle with green tea polyphenol epigallocatechin-3-gallate. Cancer Res. 2009;69:1712-1716.

31. Jemal A, Siegel R, Xu J, Ward E. Cancer statistics, 2010. CA Cancer J Clin. 2010;60:277-300.

32. Banks E. The epidemiology of ovarian cancer. In: Bartlett JMS, editor. Ovarian Cancer: Methods and Protocols. Totawa, NJ: Humana Press Inc; 2000.

33. Antoniou A, Pharoah PDP, Narod S, et al. Average risks of breast and ovarian cancer associated with BRCA1 or BRCA2 mutations detected in case series unselected for family history: a combined analysis of 22 studies. Am J Hum Genet. 2003;72:1117-1130.

34. Guterres SS, Fessi H, Barrat G, Puisieux F, Devissaguet JP. Poly (D,L-lactide) nanocapsules containing non-steroidal anti-inflammatory drugs: gastrointestinal tolerance following intravenous and oral administration. Pharm Res. 1995;12:1545-1547.

35. Duncan R. Polymer conjugates as anticancer nanomedicines. Nat Rev Cancer. 2006;6:688-701.

36. Myc A, Kukowska-Latallo J, Cao P, et al. Targeting the efficacy of a dendrimer-based nanotherapeutic in heterogeneous xenograft tumors in vivo. Anticancer Drugs. 2010;21:186-192.

37. Maeda H. Tumor-selective delivery of macromolecular drugs via the EPR effect: background and future prospects. Bioconjug Chem. 2010;21:797-802.

38. Torchilin V. Tumor delivery of macromolecular drugs based on the EPR effect. Adv Drug Deliv Rev. 2011;63:131-135.

39. Sunoqrot S, Bae JW, Pearson RM, et al. Temporal control over cellular targeting through hybridization of folate-targeted dendrimers and PEG-PLA nanoparticles. Biomacromolecules. 2012;13: 1223-1230. 
International Journal of Nanomedicine

Dovepress

\section{Publish your work in this journal}

The International Journal of Nanomedicine is an international, peerreviewed journal focusing on the application of nanotechnology in diagnostics, therapeutics, and drug delivery systems throughou the biomedical field. This journal is indexed on PubMed Central, MedLine, CAS, SciSearch ${ }^{\circledR}$, Current Contents ${ }^{\circledR} /$ Clinical Medicine,
Journal Citation Reports/Science Edition, EMBase, Scopus and the Elsevier Bibliographic databases. The manuscript management system is completely online and includes a very quick and fair peer-review system, which is all easy to use. Visit http://www.dovepress.com/ testimonials.php to read real quotes from published authors.

Submit your manuscript here: http://www.dovepress.com/international-journal-of-nanomedicine-journal 